\title{
Tramping it out: Charlie Chaplin and the Modern
}

\author{
Sonia Ghalian \\ Manipal Centre for Philosophy and Humanities, India. \\ Email: sonia.ghaliano4@gmail.com
}

Received May 17, 2017; Revised July 11, 2017; Accepted July 20, 2017; Published August 11, 2017.

\begin{abstract}
Cinema as an art form struggled to find its place in the modernist canon until the Tramp, a populist figure, established itself as the icon of modernity itself. This paper is an attempt to explore different tropes of the Tramp existing across disciples and perspectives. By understanding the politics of the characterization of the Tramp, I attempt to enter the realm of modernity through Charlie Chaplin, the ultimate Tramp who addresses modernist concerns with a critical yet humorous account of the crises of human identity in the modern world.
\end{abstract}

Keywords: cinema, tramp, Charlie Chaplin, modernity.

\section{Literary and Cinematic Modernism}

The custodians of culture were reluctant to receive Charlie Chaplin immediately, due to his explicit use of vulgar slapstick, fast action with enormous speed, expressing his hatred of authority and propriety (Gunning, 2005), present in most of his films like Gold Rush (1925), City Lights (1931) and Modern Times (1936). Ironically, it was this very same image of the Tramp, an 'everyman', that Chaplin used, which captured the modernist imagination in its true essence. The representation of the Tramp, a character straight out of the lowbrow forms ${ }^{\mathrm{ii}}$ of entertainment was able to achieve, what otherwise only high modernist literary tradition had so far achieved, that is, extraordinary modernist experiments with new aesthetic sensibilities. ${ }^{\text {iii }}$

The study of Modernism has often dealt with unbridged gap between what is considered as "high art," mainly the traditional art forms like painting, sculpture and literature; and "low art", mass-produced works such as films. ${ }^{\text {iv }}$ Literary modernism recognized and celebrated autonomous artworks and unique authorial styles which at times, downplayed certain genres and styles of writing over others. Cinema as a new form of entertainment, accommodated elements of humour, sentiment, anxiety and fear in a direct and unmediated fashion, but was not included in the modernist spectrum immediately. Films, drama and other performance arts were usually underrepresented and were considered outside of the domain of the modernist literary cannon which placed excessive emphasis on formal autonomy and stylistic innovation by this tradition (Farfan \& Kelly, 2008).

Interestingly, unlike literature and painting, cinema is not an individualist art form. Its nature is that of collective enterprise comprising of studio ownership, multiple creative minds like the - director, scriptwriter, cinematographer, and actors, having heterogeneous modes of production. Due to the high commercial aspect of the medium, cinema came to been seen as a part of popular culture. Inspite of receiving a spectacular debut with the Lumières Brothers

(C) AesthetixMS 2016. This Open Access article is published under a Creative Commons Attribution Non-Commercial 4.0 International License (http://creativecommons.org/licenses/by-nc/4.0/), which permits non-commercial re-use, distribution, and reproduction in any medium, provided the original work is properly cited. For citation use the DOI. For commercial re-use, please contact editor@rupkatha.com. 
demonstration of their film to a select Parisian audience, the movies were largely consumed as a form of entertainment designed for the masses, one which lacks the "high" modernist experimentation. It was observed, "the bourgeois passion for film, an essential prerequisite for the realization of the modernist impulse, took time to develop" (Gay, 2007, p. 362). Continuous attempts were made to assert the autonomy of film as credible of being considered a crucial art form, which has its own laws and practices.

Visionary filmmakers like Georges Mèliès and legendary performers like Charlie Chaplin rose as iconic public figures and elevated cinema to the canon of art. Motion picture came to be recognized as an 'art', peculiarly 'modern' art, through the works of film makers like D.W.Griffith, film critics like Louis Delluc. They continuously made a case for film to be judged on its own distinct qualities pertaining to aesthetics and vocabulary and were determined to shape the taste of the public with regards to films. A major debate in modernist history concerning films was about style in opposition to substance, where it became imperative to separate technique from content in order to accommodate films in the modernist tradition.

The most obvious question arising from such a discussion about cinema and modernism is about how a film, relatively a popular form of art, represents a modern world fraught with crises of meaning and fragmented consciousness. Like modernist writing, a film of this period was expected to be a social critic, cultivate a form of modernist sensibility that could represent the fears and anxieties of an alienated human condition and challenge the traditional norms of viewing the world. When cinema established its place, it shared a common goal with literary modernism, that of making meaning out of the ruptured world. The Modernist project in all forms of art- painting, literature and films were aimed to break away from conventional language and form and create alternative modes of technique to view time, space and the human consciousness with a new lens. Film, being a technological medium, particularly was concerned with technical questions of time, movement, sound and silence as well as the situatedness of the audience gaze and its impact on them.

Most of the debates in the early decades of the twentieth century were concerned with the role of language in constructing 'reality' both in literature and films. As clarified through discussions in this paper, literary modernism and films share an intrinsic relationship where one can trace social connections between high literary figures like Virginia Woolf, Gertrude Stein with cinema legends like Charlie Chaplin. For example, Stein acknowledged film as key to her historical moment and claimed that her writing had been "doing what the cinema was doing," and viewed her art as precursor to Chaplin's (cited in McCabe, 2001). Film scholar, William Verrone (2011) posits that modernist films created modes of perception that are comparable to the modernist literary text and he viewed the avant-garde film as a text to be read and interpreted. French theorist, Jean Epstein, argues that in modern literature and cinema, 'everything moves', in an aesthetic of 'mental rapidity' in which the very concept of 'the aesthetic' is inseparable from changing fashion (Marcus 2010). Similarly, Woolf in her essay "the Cinema," understood it as one which portrays "life as it is when we have no part in it," (Woolf, 1926, p. 12). Such an aesthetic understanding of cinema, allowed Woolf to explore the notion of absence in her novel To the Lighthouse (1927) where time passes and pauses in the abandoned house of the Ramsay family in the second section titled 'Time Passes.'

Another element in the modernist negotiation of experimentation was the notion of embodiment. Films, in this context, represent an embodiment which has the ability to be a whole and pieces at once. Charlie Chaplin, and his embodiment of the image of the tramp exemplify this aspect in its true sense. However, in order to understand the character of Chaplin, The Tramp, I 
would like to explore different tropes of the tramp that have existed in political, social and cultural history of the society.

\section{Tropes of the Tramp}

The most commonly and routinely designated meaning of the word Tramp, in contemporary dictionary is a man "who travels from place to place on foot, in search of employment, or as a vagrant." Another meaning explains a woman who is "sexually promiscuous." Yet such definitions do not encapsulate various other behaviors, motivations and dispositions associated with the word tramp that has a long historical trajectory.

From a historical point of view, the figure of the Tramp came into existence in America's public consciousness from the 1870 os onwards (DePastino, 2003; Kusmer, 2002; Seelye, 1963). Although nomadic laborers and wandering poor were a part of American society during the colonial times, tramping as a movement of the masses that led thousands of men on the road began during the late 18 oos. This was the period of great social and political turbulence in the climate of massive industrial transformations, which gave way to the setting up of urban life style. Effects of the Civil War had left a large number of people homeless and forced them to take the road in search of some steady income. Early attempts were made to differentiate the Tramps (migratory nonworkers) from the Hobos (men who traveled in the search of work) but no conclusive definition could be determined. ${ }^{\mathrm{v}}$

In essence, the tramp was a migratory seasonal worker who took up small time employment at growing urban enterprises but was never socially accepted in the American culture of the time. Collectively, they were seen as "Tramp evil," outsiders who were an element of nuisance and threatened the social order and moral values of American society. Characteristically, this new figure of the tramp was in polar opposition to the Victorian ideology that placed importance on values of hard work, merit, stability and familial relationships. Since, this new breed of individuals had no social and familial ties, they automatically fell on to the peripheries of society in terms of status and power. The subculture cultivated by this class of people differed from the approved middle class, in terms of jargon and standards of living. These differences were often the basis of branding them of social deviant behaviors such as alcoholism, lack of hygiene and manners and indulgence in homosexual relations. Only towards the last few years of the nineteenth century, do we see the Tramps and Hobos being looked at sympathetically for their pathetic conditions and lifestyle that was a result of the harsh effects of industrialization. ${ }^{\mathrm{vi}}$

In American literature, fictional characters that came close to represent such tramping behavior can be seen in the works of Mark Twain. In his work, often the central narrative revolves around individuals who do not have fixed permanent home, nor a steady family life and employment. Adventures of Huckleberry Finn (1884) was the first novel written and published that represented the culture of the tramp during a period of public debate about homeless men. ${ }^{\mathrm{vi}}$

The Tramp as a possible subject for fictional writing develops during the decade that had thousands of homeless men in America. Prior to this, tramps existed only in shorter narratives like "My Tramp" (1873), "My Friend, the Tramp" (1877). Through the genre of writing romantic friendship fiction ${ }^{\text {viii }}$, Mark Twain challenged and critiqued the conventional norms of American culture where Huck and Jim are excluded from the bourgeois idea of domesticity that does not have any space for homoerotic relationships to develop. Mark Twain is also credited with contrasting the trope of the tramp in his other novel A Tramp Abroad where the idea of tramping is more to do with leisure and simple life as opposed to the rationalized American modern society. 
Another trope of the tramp that can be identified in literature is in the works of the most celebrated avant-garde dramatist of the absurd, Samuel Beckett. His most performed play Waiting for Godot (1948) has two tramp like characters Gogo and Didi through whom; Beckett dramatizes the melancholy of a meaningless destiny of humankind. They wait under a solitary bare tree, talking to each other in almost repetitive dialogues for someone named Godot, whom they have never seen and who has promised to visit them. Here Godot, having a prefix of God in his name stands for all the hope and unanswerable questions troubling human mind. However, Godot never comes which implies the hopelessness and absurdity of life.

These two tramp like characters are not defined with any sense of history. They appear to be abandoned, lost vagabonds trying to find something that does not exist. In the play, the tramps continue to wait by indulging in meaningless conversations, whiling away their time by entertaining each other and dragging their feet occasionally. In this sense, Waiting for Godot is a play where nothing happens and the two acts follow an identical structure where they keep waiting for someone who does not exist. It is in this exchange that the two tramps transform into symbols of existentialism, revealing how the modern world is plagued by boredom and hopeless. Beckett when asked to explain the meaning of the play said, "If I knew (meaning), I would have said so in the play" (Gay, 2007, p. 420). This for him was the truth facing the modern state of the individual where fundamental questions about life and death are susceptible to perplexity. This absence of Godot and hope resonates the condition of modernity which is fraught with an absolute absence of certainty. ${ }^{\text {ix }}$

From a sociological perspective, a tramp is often seen as a carefree person who has gained freedom by surviving extreme conditions of poverty and discrimination, who then becomes an object for middle class projection and fantasy (Crisp, 1978). He does not have an identifiable, well-defined identity and becomes an equivalent of an inverted image of a middle-class life. He is a man who cannot fully fit into the upper class social circle and is often seen as an object of laughter due to his eccentric of qualities telling whimsical tales, smoking old foul pipes, catching fish with no tackle or steal chickens without any hesitation or shame.

As a category, the tramp stands in direct opposition to the bourgeois businessman whose life centers on big partnerships, profit making enterprise, social parties and a lot of cocktails. This contrast between the 'haves' and the 'have nots' can be critically understood through the figure of the tramp from whom the world of plenty cannot escape the dissatisfaction that lies beneath the glamour and the comfort of a modern lifestyle. The aloneness enjoyed by the tramp is a satire on the sadness that lies behind those glimmering faces full of pretense and make up. The tramp figure who apparently lacks in status appears to be happier as compared to the tortured faces in the party. This is the manner in which the tramp satirizes the middle-class individual's aspiration which is more concerned with economic liberation rather than spiritual learning. The extreme individualism developing in modern society is thus subverted through the image of the tramp as it reveals loss and alienation devoured of any real and meaningful relationships.

In order to comprehend the sensibility of a Tramp, Salvato (2006) draws qualities persistently attributed to Tramps from the character of Linda Fiorentino as Bridget in the film The Last Seduction (1994). To begin with, the Tramp's miserable condition of deprivation is the source of his success. For instance, Chaplin is able to save the rich businessman from committing suicide in the film City Lights (1931) due to his wandering on the street at night in search for food and shelter. Since vagrant tramps are represented as clowns, who are free from popular normative forms of work, this allows them space for game- play like slapstick, pantomime among others. Tramps are also depicted as insincere, as liars who can lie to another just to serve their purpose. 
They are also able to emotionally detach themselves that helps in movement from one place or person to another without any feeling of guilt or responsibility.

The characteristics of mobility associated so strongly with the figure of the Tramp, cannot escape the politics of gender embedded within it. Like mentioned earlier, meaning of the female tramp in contemporary understanding has negative connotations with regards to her sexuality. Historically, during the period of "Tramp scare" in America (late 188os), female tramps and Hobos were marginalized in terms of mobility that restricts certain spaces for women since the "act of moving is reflected in and constructed through different bodies" (Cresswell, 1998, p. 179). One can say that, the American tramp class of people was predominantly one sex group with hardly any women and occasionally if they were identified, they mostly and immediately came to be defined by their sexuality. ${ }^{\mathrm{x}}$

They faced discrimination at the hands of the society who branded them as sexual outcaste and were also sexually threatened by the male tramps. Even in literature, the idea of a 'flaneur' (the modern bohemian hero strolling freely in new archetypal modern spaces) is masculine associated with the poet Charles Baudelaire. ${ }^{\mathrm{xi}}$ In this sense, both life on the road and modernity were a masculine prerogative.

Sociologists have also suggested tramping to be a common trait among teenagers due to personal crises like family conflict, oppressive educational system, failed love and other related problems of growing up (Anderson, 1923). Youth then turn to "trips" as an outlet for their alienation which could include either eloping home, or indulging in habits like drugs and alcohol. Sometimes, Wanderlust in youth can also occur due to the literature or other forms of media they consume which influences their way of life. ${ }^{\text {xii }}$

From the above sections, we see how the trope of the tramp has been part of various cultural representations across history. One can see how the perspectives and narratives, around the Tramp are intrinsically linked to the idea of the 'modern,' that depicts the fragmented human identity, displacement and alienation in an increasingly industrialized society. Such historical characterizations of the Tramp seem to be that, through which Chaplin was able to construct the 'modern' genius of the Tramp.

\section{The 'Modern' Genius of the Tramp}

An odd looking little man, with a derby hat, ill-fitted costume, baggy pants, tight cutaway coat, over-sized shoes, and toothbrush moustache walks in with a stick to occupy the cinematic screen for the first time as a Tramp in the film Kid Auto Races at Venice (1914). Since then, the image of the Tramp is synonymous with Charlie Chaplin. Chaplin was familiar with the character of the Tramp due to his history of encounters with tramp comedians of the British hall music scene as well as the tramps he met during his childhood. Having the experience of being a theatrical mime entertainer since the age of 14 in vaudeville theatres, acting came naturally to Chaplin. He brought along with him, various traditional theatrical forms into the emerging medium of cinema and thus developed a new aesthetic sensibility for the cinematic form. The paradox of Chaplin's cinematic genius, that which made him the most enduring comedian of motion picture and led to him being taken seriously as an artist, was his use of the figure of the Tramp.

We see that it was through the image of the Tramp that Chaplin initiates a radical shift in movie making, of turning the subjectivity inwards by establishing a direct contact with the camera and the viewer. According to Hanks (2013), Chaplin creates the subject of the film by 
making himself the main subject of the camera by all means. His bodily gestures have their own specific relationship with the camera which then transforms the medium both externally and internally. This paper argues that, in being able to use the camera as camera and call for direct attention from the spectator, the trope of the Tramp becomes central to Chaplin's cinematic project. Through this character who could transform from a noman to an everyman, Chaplin blurred the boundary between the actor and the audience. This becomes possible because the Tramp does not lie outside the audience but is one of them. He travels so quickly into the realm of the familiar yet estranged, representing the individual who is caught in the new mechanical marvel of the modern world. Such inventiveness in Chaplin, whose body was a symbolic amalgamation of human and machine simultaneously, was seen by many filmmakers and critics like Louis Aragon and Louis Delluc as an embodiment of modernity itself. ${ }^{\text {xiii }}$ For instance, in the film, The Kid (1921), Chaplin performs the traditional clown's role of affirming body needs against social convention, while his physical nature transcends his human identity into a mechanical one. In the narrative of his films, it appears that Chaplin impersonates multiple sides as a tramp. He is at once, a gentleman, a poet, a dreamer, a lonely fellow, a hopeful romantic and adventurer. These traits are characteristics that coincide with the modernist commitment as well.

What is striking about this cinematic body of the Tramp is that it defies all necessity of verbal language. The rhythm, gestures, and facial expressions that convey pathos of slapstick comedy through the trope of the Tramp seem effective in transgressing social boundaries for the outsider as a critique of the very system from within. Humour, which is the central element of this Tramp, becomes a vehicle for Chaplin to complicate the conventional definition of sanity and insanity.

The mannerisms of the walk that the Tramp carries by throwing his legs and knees apart gets the audience in splits of laughter the moment he appears on screen. His queer walk also has child-like connotations and episodes of him hiding stolen eggs in his pants and later smashing them all over in his pants leaves the audience holding their stomach of laughter. Similarly, in Modern Times, the factory worker is literally represented as a cog in the machine who is driven mad by the repetitive, dehumanizing task on a conveyor belt. The individual is thus substituted for a guinea pig to test a machine in order to feed workers. The owner who controls the factory production and the movement of the body, also then becomes the owner of the Tramp's body which twists and turns continuously to tighten the bolts of the conveyor belt. By this kind of appropriation and employing his rhythmic machine like body, Chaplin explores the filmic space of the screen and in the process, revolutionizes the film form itself.

His predecessors mostly relied on the plot, events chasing events in order to keep the viewer interested but Chaplin who directed and acted in his own creations did not restrict himself from experimenting with the form. He used his body as an extension of himself to become the unmatched clown. The metaphor of the clown has certain embedded meanings with regards to appropriation of the body in the cultures of carnival. ${ }^{\text {xiv }}$ This body that Chaplin carries as the clown triumphs over sentimentality and exemplifies comedy which is very literal. His explosive body makes excessive gestures that are both seen and heard in spite of being a silent film, for instance, the use of bodily sounds in Modern Times where the stomach creates bubbling sounds of digestion. This celebration of the body over human speech is a paradox in itself since it goes against the cultural tendency of the 'modern.' The body as a natural entity assumes a mechanical posture and rhythm that breaches the codes of repression and critiques the very 'modern' world it is a product of. As Gunning (2005) states, "the natural body has a modernist dimension, one closely related to the modern preoccupation of portraying the physical body in its grotesque, 
rather than idealized forms, an impulse evident in key modern works by Degas, Schiele and Picasso, among others." This unique combination of the natural and mechanical places Chaplin in the modernist tradition which is layered with multiple meaning and invites the viewer for interpretation.

But is this fame all due to his mere physical talent at performance or is there more to it. The genius of Chaplin's enigma lay in the character he selected to bring his ideas to the world. Would Chaplin have been able to carry his modernist project to critique the monotonous mechanical world in the same manner without the presence of the trope of the Tramp? All our previous discussions about different tropes of the tramp across literature, sociology, gender and psychological perspectives unravel certain characteristics of framing the idea of the tramp that let Chaplin become the iconic Tramp in the cinematic imagination.

This image of Chaplin, the tramp in its physical, psychological and cultural aspect is designed to replicate the modern world which is dislocated, aimless, distracted and impoverished in the hyperbolic mechanical schemes of things and escapes any real emotion and attachment. The displaced individual that Chaplin identifies through the figure of Tramp is the common man in the audience. He portrays the struggles of a common individual who is also struggling to make meaning of the order of the new world which threatens his life in the wake of rapid industrialization. The common man, who now has become an outsider in his own society, dazzles with speed and action on screen to imitate the changing reality of contemporary life, one of technological development and growing commodification. With this understanding, "a man on the fringe of society, yet capable of seeing clearly to its center," (Susman, 1984, p. 78) was made a hero by Chaplin through the persona of the Tramp.

Another aspect that lingers in my thoughts of my understanding of the trope of tramp is that modernism as a historical period as well as an aesthetic movement saw the birth of a radical new subject. He is a subject, who is no longer in the model of the sophisticated Renaissance man of letters. But he is rather an ordinary individual who is able to reflect upon the complexities of modern times with minimal elements. The language and techniques that Chaplin, The Tramp embodies is that of silence and humour. Such an embodiment was able to invite a larger viewership to the realm of modernist thought, opening up critical spaces to the general public, that were till now restricted to the stalwarts of high intellectualism.

In this sense, film as a medium and Chaplin in particular is responsible for having introduced critical thought and modernist sensibilities to the common man. The technological innovations of the time which led to the development of films, an intriguing new method of delivering radical content to the masses through images inaugurates not only the radical new subject but a radical new world along with its own unique ways of seeing and being in the world.

\section{Notes}

${ }^{\mathrm{i}}$ A corpus of work has been done with regards to taking relationship between film and literature in Modernism such as Susan McCabe, Cinematic Modernism: Modernist Poetry and Film (Cambridge: Cambridge University Press, 2005), David Trotter, Cinema and Modernism, (London: Backwell Publishers, 2007).

ii Tramp character is a product of Vaudeville and burlesque theatre which are considered lowest form of lowbrow entertainment. 
iii Modernist aesthetic sensibilities include new taste and modes of expression in arts such as Cubist paintings of Picasso, novels of Virginia Woolf written in Stream of Consciousness style.

iv Theorists like Kamilla Elliott. Rethinking the Novel/Film Debate, (New York: Cambridge, 2007), Herbert Hans, Popular Culture and High Culture, (New York: Basic Books, 1974) have studied the debates about high and low art.

${ }^{v}$ Definition explained in the work of Time Cresswell, The Tramp In America (London: Reakton Books, 2013).

vi There are Tramp ethnographic studies that chronicle the social realities of these marginalized workers who were also a metaphor for social division and industrial chaos (Stanley 1992, Keyssar 1986, Katz 1983, Reed 1992).

vii Nineteenth century literature studies with regards to Mark Twain and the trope of tramp and homeless man has been done by scholars like Alex Nissen, "A Tramp at Home: Huckleberry Finn, Romantic Friendship, and the Homeless Man”, 6o (2005): 57:86;

Peter Messent, "Tramps and Tourists: Europe in Mark Twain's A Tramp Abroad,"34 (2004): 138:154.

viii Other romantic fictional novels include Charles Dicken's David Copperfield (1849-50), John Godfrey's Fortunes (1864), Adventures of Tom Sawyer (1876).

ix See Edith Kern, “Drama stripped for Inaction: Beckett's Godot,” Yale French Studies, No 14, P 4147.

${ }^{x}$ See Heather Tapley, "In search of the Female Hobo," Atlantis 34.1 (2009): 58-67.

xi Baudelaire, Charles. The Painter of Modern Life and Other Essays. Trans. Jonathan Mayne New York: Phaidon, 1964.

${ }^{x i i}$ Reminiscent accounts in literature like Josiah Flynt's Tramping With Tramps, Adventure and philosophy of life of as represented in American biographical drama survival film Into the Wild (1996), based on the non fiction book by Jon Krakauer.

xiii Man-machine comedy through the works of Charlie Chaplin analyzed in the works of Danius, S. The Senses of Modernism: Technology, Perception and Aesthetics. London: Cornell University Press, 2002; North, M. Machine-Age Comedy. Oxford: Oxford University Press, 2009.

${ }^{\text {xiv }}$ William Paul's essay, "The Annals of Anality” has used Mikhail Bhakthin's analysis of culture of carnival and the place of the body to understand Chaplin's body of laughter. (cited in Gunning 2005).

\section{Acknowledgement}

This paper is a result of many conversions and feedback she received from her professors $\mathrm{Dr}$ Nikhil Govind and Dr Gayathri Prabhu.

\section{References}

Cresswell, T. (1999). Embodiment, Power and the Politics of Mobility: The Case of Female Tramps and Hobos. Transactions of the Institute of British Geographers, 24, 175-192.

Crisp, P (1978). The Existentialist and the Tramp. The Crane Bag, 2, 142-147.

Farfan, P. \& Kelly, K. (2008). Staging Modernism. South Central Review, 25, 1-11.

Gay, P. (2009). Modernism: The Lure of Heresy. London, England: Vintage.

Gunning, T. (2005, July). Chaplin and the Body of Modernity. Paper presented at the BFI Charles Chaplin 
Conference, London. Retrieved from http://chaplin.bfi.org.uk/programme/conference/pdf/tomgunning.pdf

Hanks, S. (2013). The birth of the tramp: Chaplin, gesture, and the rhythms of modernity. Postgraduate English Journal, 26, 1-26.

Marcus, L. (2010). The Tenth Muse: Writing about Cinema in the Modernist Period. London, England: Oxford.

Salvato, N. (2006). Tramp Sensibility and the Afterlife of Showgirls. Theatre Journal, 4, 633-648.

Susman, W. (1984). Culture as history: the transformation of American society in the twentieth century. New York, NY: Pantheon Books.

Verrone, W. (2011). The Avant-Garde Feature Film: A Critical History. London, England: McFarland \& Company.

Sonia Ghalian is a PhD scholar in India at the Manipal Center for Philosophy and Humanities, Manipal University. Her current research under the subject of 'Children's films in India' attempts to explore the nuances of representing children and childhood stories in the cinematic medium in the larger continuum of Indian cinema. This thesis aims to place the category of children's film in India in conversation with the global cinema for children and also make a case for incorporating media literacies (in this case films) in the pedagogical practices for young children in education in India. 